\title{
Penicillin $\mathrm{V}$ did not shorten symptoms in children with sore throat
}

Zwart S, Rovers MM, de Melker RA, et al. Penicillin for acute sore throat in children: randomised, double blind trial. BMJ 2003;327:1324-7.

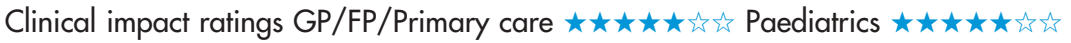

In children 4-15 years of age with a sore throat, is penicillin V (PCV) for 3 (PCV3) or 7 (PCV7) days more effective than placebo for reducing the duration of symptoms (DOS)?

\section{METHODS}

-

Design: randomised placebo controlled trial.

Allocation: concealed. *

Blinding: blinded (patients and healthcare providers).*

Follow up period: 7 days.

Setting: 43 family practices in the Netherlands.

Patients: 156 children $4-15$ years of age (mean age $10 y, 50 \%$ boys) who had a sore throat for $<7$ days and $\geqslant 2$ of 4 Centor criteria (history of fever, absence of cough, swollen tender anterior cervical lymph nodes, and tonsillar exudates). Exclusion criteria: imminent quinsy, scarlet fever, requirement of antibiotics, and intolerance to penicillin. $62 \%$ had a positive culture for group A streptococci (GAS).

Intervention: PCV7 $(n=46), P C V 3(n=54)$, or placebo for 7 days $(n=56)$. The dosage was one $250 \mathrm{mg}$ capsule 3 times daily for children 4-10 years of age and two $250 \mathrm{mg}$ capsules 3 times daily for children $\geqslant 10$ years of age.

Outcomes: DOS (defined as the number of days of symptoms
after randomisation until the pain had resolved permanently) and after randomisation until the pain $\mathrm{h}$
eradication of the initial pathogen.

Patient follow up: $85 \%$ at 7 days.

*See glossary.

\section{MAIN RESULTS}

Analysis was by intention to treat. Among all children combined and in children without GAS, PCV did not differ from placebo for DOS (table). In the subgroup of children with GAS, the mean DOS was greater in the PCV3 group than in the placebo group, but the PCV7

For correspondence: Dr S Zwart, Julius Center for Health Sciences and Primary Care, Utrecht, The Netherlands. S.Zwart@med.uu.nl

Sources of funding: Groene Land Achmea Health Insurances and Stichting Gezondheidszorgonderzoek Ysselmond. group did not differ from the placebo group (table). The rate of GAS eradication was greater in the PCV7 group than in the placebo group $(68 \%$ v $28 \%, \mathrm{p}<0.05)$.

\section{CONCLUSION}

In children 4-15 years of age with a sore throat, penicillin $\mathrm{V}$ for 3 or 7 days was not better than placebo for reducing the duration of symptoms.

\section{Commentary}

Z wart et al have made an important addition to the existing literature because only 3 studies have been previously done in children. ${ }^{1}$ The conclusion in the Cochrane review by Del Mar et al was that children do not differ from adults and that the benefit of PCV is modest. The prevention of complications was also limited. The study by Zwart et al differs in that it did not find any difference between the PCV and placebo groups with respect to DOS. However, a moderate difference in the rates of complications was observed.

The study raises some important questions. ${ }^{2}$ Firstly, the use of $\geqslant 2$ Centor criteria: the authors hold that these criteria have not been validated in a population of children. In another study of adult patients, the authors used 3 or 4 criteria for patient inclusion and thus had a population with a greater degree of disease. ${ }^{3}$ Secondly, the use of throat swabs for detecting GAS may be of limited value especially in children where the carrier rate is even greater than that in adults. Thus, subgroups of children who have immunologically manifest disease may derive greater benefit from PCV than those studied by Zwart et al. To single out these patients, it is necessary to evaluate the Centor criteria and other clinical features in patients with immunologically confirmed disease.

The authors also found that the DOS was greater in the PCV3 group than in the placebo group, an odd finding that was also observed in a previous study of adult patients. ${ }^{3}$ The authors' explanation was that a short course of PCV only reduces the natural immune response without eradicating the GAS.

This study will reinforce the reluctance of clinicians to give PCV to children with sore throat even if a GAS infection is confirmed. In clinical work, shared decision making with the parents or delayed prescription is a good strategy in children who are not so ill. As stated by the authors, the few patients who have complications can be treated when these occur.

Morten Lindbaek, MD

University of Oslo Oslo, Norway

1 Del Mar CB, Glasziou PP, Spinks AB. Cochrane Database Syst Rev 2000;(4):CD000023.

2 Little P. BMJ 2003:327:1327-8.

3 Zwart S, Sachs AP, Ruijs, et al. BMJ 2000;320:150-4.

Penicillin V (PCV) for 7 days (PCV7) or 3 days (PCV3) v placebo in children 4-15 years of age with a sore throat at 7 days*

\begin{tabular}{|c|c|c|c|c|c|}
\hline Outcomes & Culture results & $\mathbf{n}$ & Comparison & Means & Difference between groups $(95 \% \mathrm{Cl})$ \\
\hline $\begin{array}{l}\text { Duration of sore } \\
\text { throat symptoms (d) }\end{array}$ & $\begin{array}{l}\text { All children } \\
\text { Positive for group A streptococci } \\
\text { Other or negative for group A } \\
\text { streptococci }\end{array}$ & $\begin{array}{l}156 \\
96 \\
60\end{array}$ & $\begin{array}{l}\text { PCV7 } v \text { placebo } \\
\text { PCV3 } v \text { placebo } \\
\text { PCV7 } v \text { placebo } \\
\text { PCV3 } v \text { placebo } \\
\text { PCV7 } v \text { placebo } \\
\text { PCV3 } v \text { placebo }\end{array}$ & $\begin{array}{l}3.8 v 3.8 \\
4.6 \vee 3.8 \\
3.0 v 3.5 \\
4.8 v 3.5 \\
4.9 \vee 4.7 \\
4.4 v 4.7\end{array}$ & $\begin{array}{r}0.0(-0.9 \text { to } 0.9) \\
0.8(-0.1 \text { to } 1.7) \\
-0.5(-1.5 \text { to } 0.6) \\
1.3(0.2 \text { to } 2.4) \dagger \\
0.2(-2.0 \text { to } 1.6) \\
-0.3(-1.4 \text { to } 1.9)\end{array}$ \\
\hline
\end{tabular}

${ }^{*} \mathrm{Cl}$ defined in glossary.

†Significant outcome favours placebo. 